\title{
Addition of Illuminator Fiber Optic to Produce 3 Dimension Effects in Micrographic Observation Using Upright Microscope
}

\author{
Sutriyono $^{1, *}$, Widodo $^{2}$, Retno Suryandari ${ }^{2}$ \\ ${ }^{1}$ Integrated Laboratory; ${ }^{2}$ Biology Education Department, Faculty of Science and Technology, UIN Sunan Kalijaga \\ Jl. Marsda Adisucipto Yogyakarta 55281 Tel. + 62-274-519739 \\ Email*: sutriyono@uin-suka.ac.id
}

\begin{abstract}
Microscope is one of the tools used in practicums with high intensity. The use of a microscope adjusts to the object to be observed in order to obtain optimal micrographic results. Stereo microscopes are used to observe three-dimensional objects. Upright microscopes are used to observe two-dimensional objects. This study aims to combine the two advantages of stereo microscopy that can produce three-dimensional micrography with the advantages of an upright microscope that has a high total magnification. The method used in this study is an experimental method by adding an optical fiber illuminator in the use of an upright microscope and then applying it in various observations. The conclusion of this research is the addition of an optical fiber illuminator in observations using an upright microscope can replace the function of a stereo microscope; can produce three-dimensional effects and increase magnification in Daphnia magna micrographic observations.
\end{abstract}

Keyword: Upright microscope, stereo, optical illuminator, Daphnia magna

\section{INTRODUCTION}

Microscope is high intensity used tools in practical lesson. Microscope is laboratory tools which is commonly used both in university degree and high school. The development of microscope was very rapid and vast, start with monocular, binocular, and trinocular. The rapid development were also in the light source of microscope, from the sun light, electricity lamp, and electron.

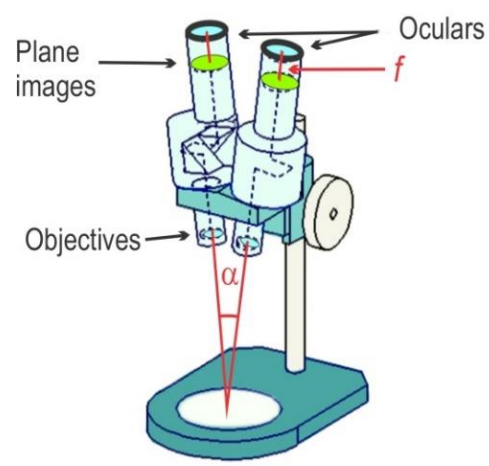

Figure 1. Principle of Stereo Microscope.

(source: https://www.intechopen.com/books/advances-in-stereovision/perception-and-reality-in-stereo-vision-technological-applications)

The use of microscope can be adjusted to the observed objects to gain the optimum result of micrography. Stereo microscope were used to observe 3 dimension object. On the other hand, upright microscope were used to observe 2 dimension object. However, stereo microscope and upright microscope have different principle of work. Stereo microscope can produce 3 dimension micrography using the light reflection from the objects. Stereo microscope used the light from the object tray. The reflection was formed by the reflection of 3 dimension object. Reflected light from the object were caught by objective lense and passed to ocular lense. However upright microscope were use the light under object tray, then passed through the object, caught by objective lense and passed through the ocular lense.

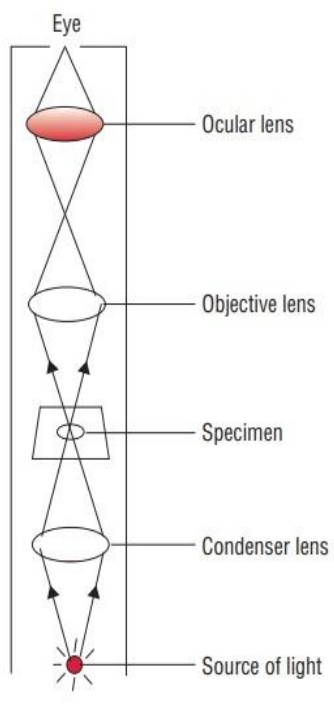

Principle of compound light microscope.

Figure 2. Upright Microscope.

(source: https://www.brainkart.com/article/Light-microscopy_17818/)

Microscope that usually used in high school degree were monocular or binocular upright. Otherwise in university practical lesson, the objects can be varied, for example object slide and 3 dimension object. To 
optimize the result, upright microscope need to be modified to stereo microscope to enhance it ability in observing 3 dimension objects. Stereo microscope was commonly used to observe living objects, transparent objects, and 3 dimension objects. The examples are Hydra sp, Daphnia magna, Anabaena azzolae, etc.

\section{METHODOLOGY}

The research was conducted in Integrated Laboratory, Faculty of Science and Technology, UIN Sunan Kalijaga Yogyakarta. Materials that were used in this research were stereo microscope, upright microscope, Optilab Camera, illuminator fiber optic, Daphnia magna, and glass ware.

The research was started with understanding literature about microscope, especially in the term of the working principle and illuminator fiber optic. Field study were conducted to detect the location of Daphnia magna. The laboratory work was started by observe Daphnia magna sample using stereo microscope in addition of illuminator fiber optic for light resource. It continued with observe the sample with upright microscope, made the report, and made the conclusion.

\section{RESULT AND DISCUSSION}

The result of this research was micrography of Daphnia magna using stereo microscope and upright microscope with addition of illuminator fiber optic as light resource.

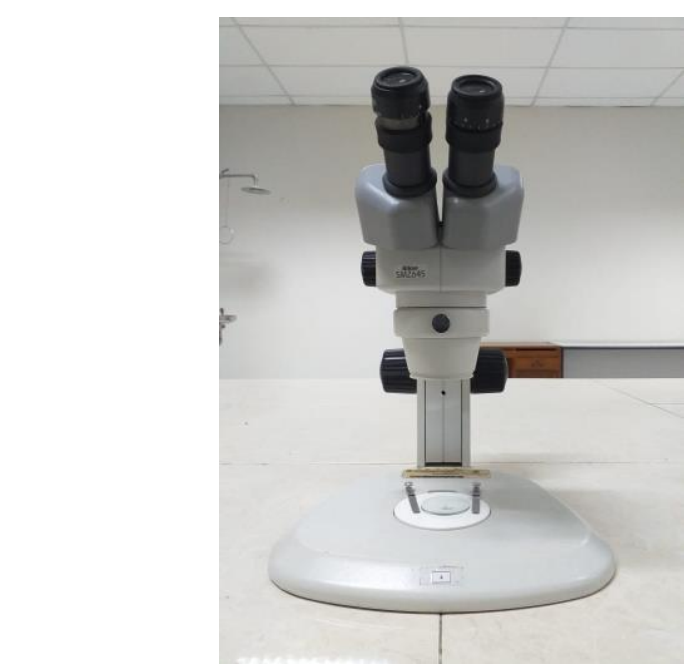

Figure 3. Stereo microscope.

The spesification of the stereo microscope in this research as described below :

- Ocular lense 10x magnification

- Objective lense 1x magnification, can be increased with 5x zoom

- The result was 3 dimension micrography

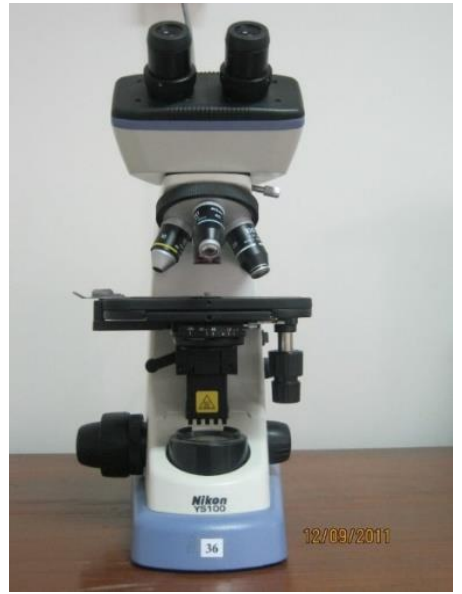

Figure 4. Upright microscope.

The spesification of the microscope in this research as described below:

- Ocular lense with 10x magnification

- Objective lense with 4x, 10x, 40x and 100x magnification (maximum magnification is 1000x)

- The result was 3 dimension micrography

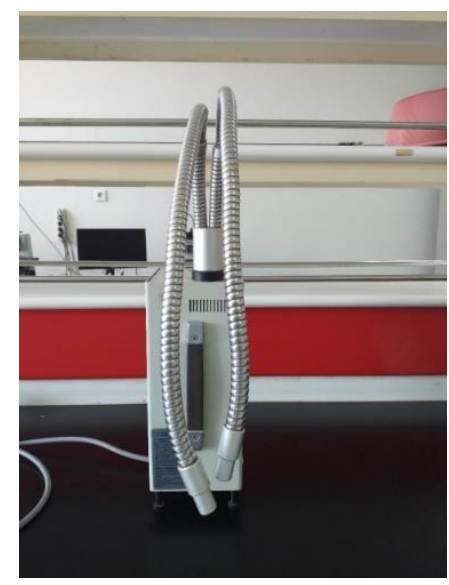

Figure 5. Iluminator fiber Optic.

The figure above is the illuminator fiber optic that can be used as the light resource. It can be modified or adjusted based on the object.

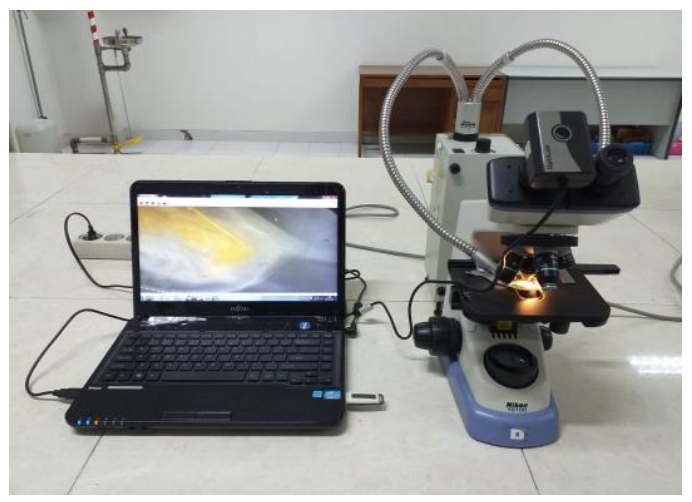

Figure 6. Upright microscope, illuminator fiber optic, Optilab, and laptop. 
The figure above shows the modified upright microscope, connected to some tools to observe the Daphnia magna specimen. The result was documentation in a form of photo. In common used, upright microscope were not complemented with illuminator fiber optic because the light resource were from LED light below the object tray.

Illuminator fiber optic were added in this research as the light resource to replace the LED lamp.

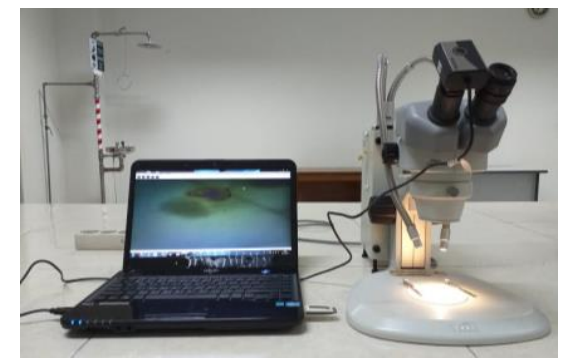

Figure 7. Stereo microscope, illuminator fiber optic, Optilab, and laptop.

The figure above shows the stereo microscope, connected to some tools to observe the Daphnia magna specimen. In common used, illuminator can be replaced with other light resource.

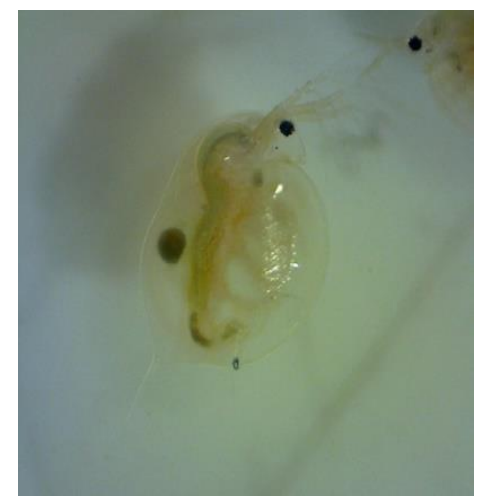

Figure 8. Micrography of Daphnia magna from the stereo microscope.

Figure above shows optimum micrography from the stereo microscope with total magnification was 20x. The use of zoom with total magnification of more than $20 x$ were produce not optimal result.

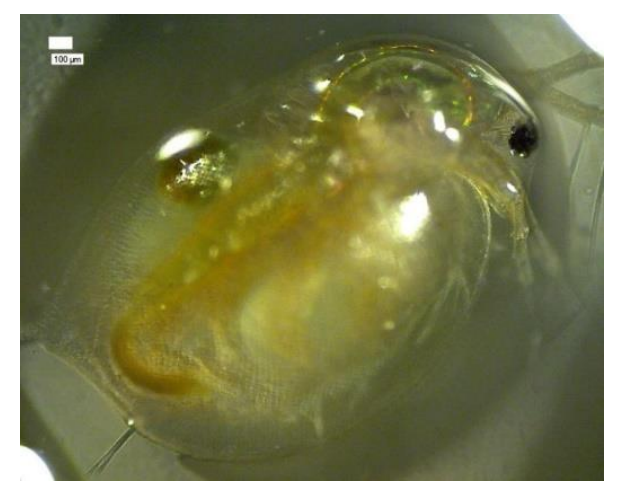

Figure 9. Micrography of Daphnia magna from upright microscope with modification in light resource using illuminator fiber optic.
Figure 9 shows the optimal micrography of Daphnia magna using upright microscope in 40x total magnification (10x ocular lense and 4x objective lense). The result was not optimum in other magnification. The result were not detail in smaller magnification. Otherwise, the whole body of Daphnia magna can't be observed using higher magnification.

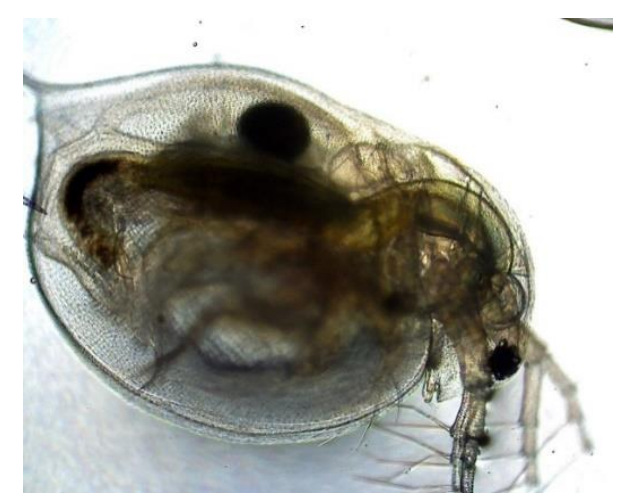

Figure 10. Micrography of Daphnia magna using upright microscope without addition of illuminator fiber optic.

\section{Comparison of Figure 8, 9, and 10}

Daphnia magna is micro planctonic from genus Crustacean. It commonly mentioned as water flea because the way it moves in the water. Figure 8 is the result of Daphnia magna observation with general stereo microscope. Figure 9 is observation with general upright microscope. Figure 10 is observation with upright microscope with addition of illuminator fiber optic. Figure 9 was the best among all of the results. The picture was clear, with highest resolution. It can be applied in high school laboratory work. The stereo microscope can be combined with illuminator fiber optic as the light resource. The light resource were come from above the object tray (common principle of microscope).

\section{CONCLUSION}

The addition of illuminator fiber optic in observation using upright microscope can replace the stereo microscope. It can produce 3 dimension effect and increase the magnification in observation of Daphnia magna micrography.

\section{REFFERENCES}

Andreas Ch. Louk, G.B. Suparta, Hadi I. Sutaji (2017). Pemutakhiran Mikroskop Cahaya Monokuler Menjadi Mikroskop Digital Untuk Pembelajaran Siswa SMA/ Sederajat.Jurnal Fisika Sains dan Aplikasinya.Vol.2. No.2 hal 101-104.

Douglas B. Murphy (2001). Fundamentals of Light Microscope Light Microscopy and Electronic Imaging. A John Wiley \& Sons, Inc. 
Henneke Pangkey (2009). Daphnia dan Penggunaannya. Jurnal Perikanan dan Kelautan.Vol V no.3, hal 33-36

Jordan Kreindler. R (2017). The Stereo Microscope (Part 1: Introduction and Backgroud $3^{\text {rd }}$ Edition. http://www.microscopy-uk.org.uk/mag/artjun12/jk-stereo1.pdf

MirkoRuscic, Antonio Vidovic, Goran Kovacevic and Damir Sirovina (2018). The Use of Microscope in School Biologi Teaching. Resolution and Discovery 3 (1). pp. 13-16

Michael Hoppert (2003). Microscope Techniques in Biotechnology. GmbH \& Co. KGaA, Weinheim.

R. M. Allen (1940). The Microscope.D. VanNostrand Company, Inc.

Yilmaz Kara (2018). Determining the Effects of Microscope Simulation on Achievement, Ability, Report and Opinions about microscope in General Biology Laboratory Course.Universal journal of Educational Research (9): 19811990
Anonim. Introduction to Light Microscopy. https://www.microscopyu.com

https://www.intechopen.com/books/advances-in-stereovision/perception-and-reality-in-stereo-vision-technologicalapplications accessed date November, 072019

https://www.brainkart.com/article/Light-microscopy_17818/ accessed date November, 072019

http://www.fibersystems.com/pdf/whitepapers/Basics-of-FiberOptics.pdf accessed date February, 122020

https://www.maxmanroe.com/vid/teknologi/internet/pengertianfiber-optik.html accessed date February, 122020

https://www.reading.ac.uk/web/files/biosci/Culturing_Daphnia_20 1KB.pdf accesseed date February, 122020

https://bitesizebio.com/25556/brightness-and-contrast-inmicroscopy-imaging/ accessed date February, 122020 